\title{
Modeling Human Epilepsy by TALEN Targeting of Mouse Sodium Channel Scn8a
}

\author{
Julie M. Jones and Miriam H. Meisler* \\ Department of Human Genetics, University of Michigan, Ann Arbor, Michigan \\ Received 9 October 2013; Revised 21 November 2013; Accepted 25 November 2013
}

\begin{abstract}
Summary: To evaluate the efficiency of TALEN technology for introducing mutations into the mouse genome we targeted Scn8a, a member of a multigene family with nine closely related paralogs. Our goal was to generate a model of early onset epileptic encephalopathy by introduction of the Scn8a missense mutation p.Asn1768Asp. We used a pair of TALENs that were highly active in transfected cells. The targeting template for homologous recombination contained a $4 \mathrm{~kb}$ genomic fragment. Microinjection of TALENs with the targeting construct into the pronucleus of $\mathbf{3 5 0}$ fertilized mouse eggs generated 67 live-born potential founders, of which $\mathbf{5}$ were heterozygous for the pathogenic mutation, a yield of $7 \%$ correctly targeted mice. Twenty-four mice carried one or two Scn8a indels, including 12 frameshift mutations and the novel amino acid deletion p.Asn1759del. Nine off-site mutations in the paralogs sodium channel genes Scn5a and Scn4a were identified. The data demonstrate the feasibility and efficiency of targeting members of multigene families using TALENs. The Scn8a $a^{\text {tm1768DMm }}$ mouse model will be useful for investigation of the pathogenesis and therapy of early onset seizure disorders. genesis 52:141-148. (C) 2013 The Authors genesis Published by Wiley Periodicals, Inc.
\end{abstract}

Key words: encephalopathy; multigene family; mutagenesis; Nav1.6

\section{INTRODUCTION}

Mice carrying human pathogenic mutations are valuable tools for analysis of gene function, disease mechanisms, and new therapies. During the past 20 years, many pathogenic mutations have been introduced into the mouse genome by homologous recombination in embryonic stem cells (Menke, 2013). A recently devel- oped alternative technology employs sequence-specific endonucleases to target specific sites for mutagenesis. Zinc finger nucleases, transcription activator-like (TAL) effector nucleases (TALENs), and RNA guided CRISPR/ Cas nucleases generate site-specific breaks in complex genomes that are subsequently mis-repaired, either by nonhomologous end-joining to generate small insertions and deletions or by homologous recombination with a mutated template to introduce specific changes into the genome (Meyer et al., 2012; Panda et al., 2013; Yang et al., 2013). Thus far, these methods have been most often used for in vitro mutagenesis of cultured cells, including mouse ES cells. A small number of null alleles (Davies et al., 2013; Qiu et al., 2013; Sung et al., 2013) and missense mutations (Panda et al., 2013; Wefers et al., 2013) have been introduced into the mouse genome.

We used TALENs to generate a mouse model of the missense mutation p.Asn1768Asp in the neuronal sodium channel Nav1.6 encoded by the gene Scn8a. This de novo mutation was identified in a child with severe, early onset epileptic encephalopathy by whole genome sequencing (Veeramah et al., 2012). More than a dozen de novo mutations of SCN8A have since been identified by exome sequencing of patients with epileptic encephalopathy or intellectual disability, making

This is an open access article under the terms of the Creative Commons Attribution-NonCommercial-NoDerivs License, which permits use and distribution in any medium, provided the original work is properly cited, the use is non-commercial and no modifications or adaptations are made.

* Correspondence to: Miriam Meisler, Department of Human Genetics, 4909 Buhl, University of Michigan, Ann Arbor, MI 48109-5618, E-mail, meislerm@umich.edu

Contract grant sponsor: NIH, Contract grant number: R01 NS 034509

Published online 28 November 2013 in

Wiley Online Library (wileyonlinelibrary.com).

DOI: $10.1002 / \mathrm{dvg} .22731$ 
Scn8a a significant new source of neurological disease (Allen et al., 2013; Carvill et al., 2013; Rauch et al., 2012). In addition to de novo mutations, a heterozygous null mutation of $S C N 8 A$ cosegregated with cognitive impairment in a human pedigree (Trudeau et al., 2006). Heterozygous null mutations in the mouse also result in behavioral abnormalities (McKinney et al., 2008).

$S C N 8 A$ is a member of a highly conserved multigene family encoding nine paralogous sodium channels, 7 expressed in neurons and 2 expressed in muscle (Catterall et al., 2008; Meisler et al., 2010; Zakon, 2012). $S C N 8 A$ encodes the sodium channel Nav1.6, which is abundant in the central and peripheral nervous systems (O'Brien and Meisler, 2013). Nav1.6 is localized at nodes of Ranvier and at the axon initial segment, where it regulates neuronal firing (Boiko et al., 2001; Lorincz and Nusser, 2008; Van Wart et al., 2007).

The previously described mouse mutants of Scn8a result from partial or complete loss of function mutations (O'Brien and Meisler, 2013). In contrast, the human epilepsy mutation p.Asn1768Asp exhibits a dominant gain-of-function due to impaired channel inactivation (Veeramah et al., 2012). A mouse model of p.Asn1768Asp will provide novel information regarding the in vivo effects of Scn8a hyperactivity and the pathogenesis of epileptic encephalopathy.

\section{RESULTS AND DISCUSSION}

Six pairs of TALENs were designed to generate a double-stranded break near the targeted nucleotide c.5302A $>\mathrm{G}$ in exon 26 of $S c n 8 a$, and to maximize mismatches with the paralogous sodium channel genes. Only three of these exhibited nuclease activity in transfected NIH3T3 cells. The TALENs in Figure 1A had the highest activity and were selected for microinjection. The targeted nucleotide is located $25 \mathrm{bp}$ downstream from the predicted endonuclease digestion site in the spacer between the two TALENs (Fig. 1A, arrow). The two closest off-site matches identified by the program TAL Effector Nucleotide Targeter 2.0 Paired Target Finder (Doyle et al., 2012) are located in the paralogous genes Scn $4 a$ and Scn5a encoding sodium channels expressed in skeletal and cardiac muscle (Fig. 1C).

The targeting template for homologous recombination was constructed by cloning a 320 bp fragment derived from overlapping synthetic oligonucleotides of 190 and $184 \mathrm{bp}$. The $190 \mathrm{bp}$ oligonucleotide contained 9 single nucleotide differences from the endogenous Scn8a gene, including the nonsynonymous $A>G$ substitution encoding the p.Asn1768Asp mutation and a synonymous change in the spacer region that introduces a HincII site (Fig. 1B). Seven more synonymous changes within the TALEN binding sites were introduced in order to minimize redigestion of targeted alleles. The codon usage for each introduced codon was $\geq 9 \%$. Two flanking genomic fragments were added to the construct, a $1.5 \mathrm{~kb}$ upstream left arm and a $2 \mathrm{~kb}$ downstream right arm. The structure of the targeting construct, with restriction sites, PCR primers and hybridization probes, is shown in Figure 2A.

Two rounds of microinjection into fertilized mouse eggs were carried out using $2.5 \mathrm{ng} / \mu \mathrm{l}$ of circular targeting plasmid with two TALEN mRNAs each at $10 \mathrm{ng} / \mu \mathrm{l}$ (200 eggs) or $20 \mathrm{ng} / \mu \mathrm{l}$ (150 eggs). Sixty-seven potential founders were obtained, 20 from the first microinjection and 47 from the second. Mice carrying the introduced mutations were identified by PCR amplification of a $327 \mathrm{bp}$ fragment containing the targeted site followed by digestion with HincII (Fig. 2B). Ten of the 67 mice were positive with this assay. To distinguish between correct targeting of $S c n 8 a$ and random insertion of the targeting construct, these 10 mice were analyzed by Southern blotting of HincII digested genomic DNA. Hybridization with a probe external to the targeting construct detected a $3.5 \mathrm{~kb}$ HincII fragment in 5 correctly targeted genomic DNAs (Fig. 2C). The yield of targeted mice was 5/67 (7\%). The targeted allele is designated Scn $8 a^{t m 1768 D M m}$. Reprobing the Southern blot with a probe internal to the targeting plasmid identified 8 mice carrying random insertions of the targeting construct, recognized by the $2.2 \mathrm{~kb}$ HincII fragment from within the construct (Fig. 2C). Three of the random insertions occurred in mice that also carried a correctly targeted allele. The other 5 mice with random insertions had high copy inserts that interfered with molecular analysis of the endogenous Scn8a locus, leaving 62 potential founders for analysis of nontargeted mutations of Scn8a.

Sequencing the targeted site from these 62 potential founders identified 13 distinct indels in 24 mice (Fig. 3B). Eighteen mice carried a single mutant allele and 6 mice were compound heterozygotes carrying two indels (Table 1). The Scn8a indels produced frameshift mutations, with the exception of a 3 bp deletion that occurred independently in 4 mice and resulted in the amino acid deletion p.Asn1759del (Fig. 3B). The 6 mice that were compound heterozygotes for frameshift mutations exhibited the classic Scn8a homozygous null phenotype, with hind limb paralysis, muscle wasting and juvenile lethality. The incorporation into the targeting vector of 4 synonymous SNPs per TALEN binding site was apparently effective in preventing redigestion after homologous recombination, since none of the indels carried the synonymous SNPs. Eight mice appeared to be mosaic for two different indels plus the wild-type allele, as indicated by three overlapping sequences from the amplified PCR product that could not be resolved.

To detect off-site mutations in the most closely related genomic sequences, we amplified the corresponding fragments of Scn $4 a$ and Scn $5 a$ and identified 2 indels of $S c n 4 a$ and 7 indels of $S c n 5 a$ (Fig. 1C,D). (By 
A

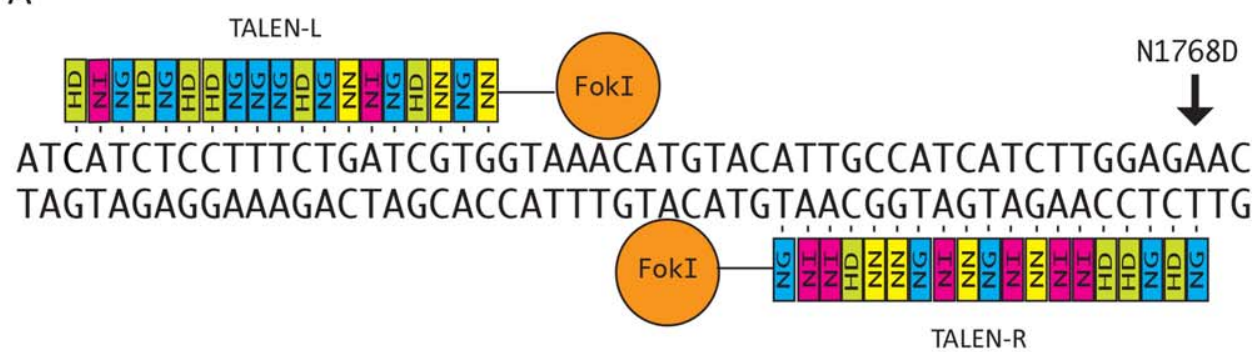

B

Wildtype

TALEN-L

TALEN-R

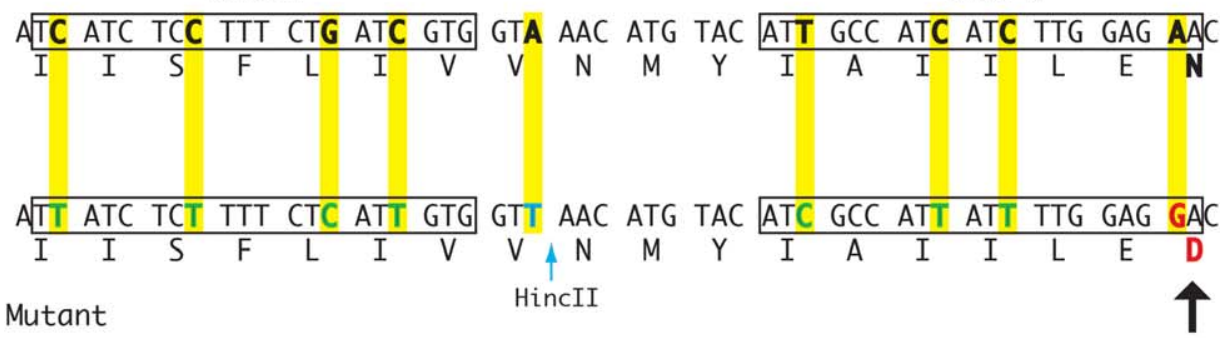

N1768D

C

\begin{tabular}{|c|c|}
\hline TCATCTCCTTTCTGATCGTGGTAAACATGTACATTGCCATCATCTTGGAGAA & $\operatorname{Scn} 80$ \\
\hline 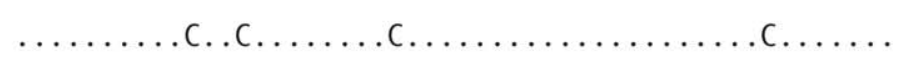 & $\operatorname{Sen} 50$ \\
\hline 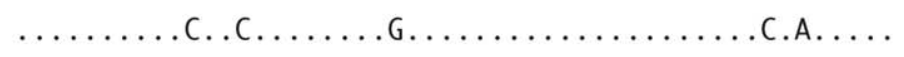 & Scn \\
\hline$\ldots C \ldots C \ldots \ldots \ldots C \ldots \ldots \ldots \ldots \ldots$ AG.G..TC.. & \\
\hline 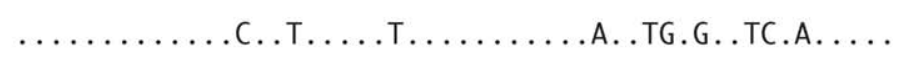 & Scn1 \\
\hline 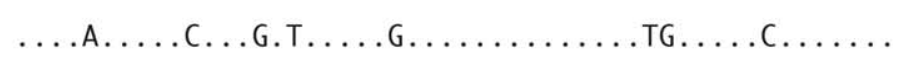 & Scn \\
\hline$\ldots$.A.......G.T....G........ & $\operatorname{Sen} 2$ \\
\hline$\ldots$........G.T...G....... & Scn \\
\hline 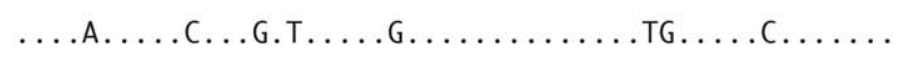 & \\
\hline
\end{tabular}

FIG. 1. TALEN binding sites in Scn8a and paralogous sodium channel genes. (A) Repeat variable diresidue (RVD) sequence for left and right TALENs directing the Fokl endonuclease to a site within exon 26 of mouse Scn8a. The HD residue (green) binds the $\mathrm{C}$ nucleotide; NI (pink) binds A; NG (blue) binds T; NN (yellow) binds G. The targeted nucleotide for introduction of the epilepsy mutation p.Asn1768Asp is marked with an arrow. (B) Nine nucleotide substitutions (yellow) were incorporated into the targeting construct to prevent redigestion after homologous recombination with the targeting construct. One substitution introduced the Hincll site used for genotyping (blue arrow). (C) Sequences of the TALEN targeted site in paralogs from the sodium channel multigene family. Dots represent sequence identity. The most closely related paralogs sites are in Scn4a and Scn5a, with 1 or 2 bp mismatches per TALEN binding site. The third closest site in the mouse genome is in Scn10a, with 5 mismatches in one binding site.

comparison, there were 37 mutant alleles of Scn8a). One 9 bp in-frame deletion of Scn $5 a$ and one 18 bp inframe deletion of $\operatorname{Scn} 4 a$ were observed. The $S c n 4 a$ and $\operatorname{Scn} 5 a$ mutations occurred in mice that also carried one or two mutations of $S c n 8 a$ (Table 1), suggesting that a subset of injected eggs expressed a high level of TALEN activity. No mutations were detected in the more divergent Scn1Oa gene, with 5 mismatches in one TALEN site (Fig. 1).

The highly efficient targeting of Scn $8 a$ observed in this study confirms the recent evidence that TALEN microinjection is a practical method for introducing 


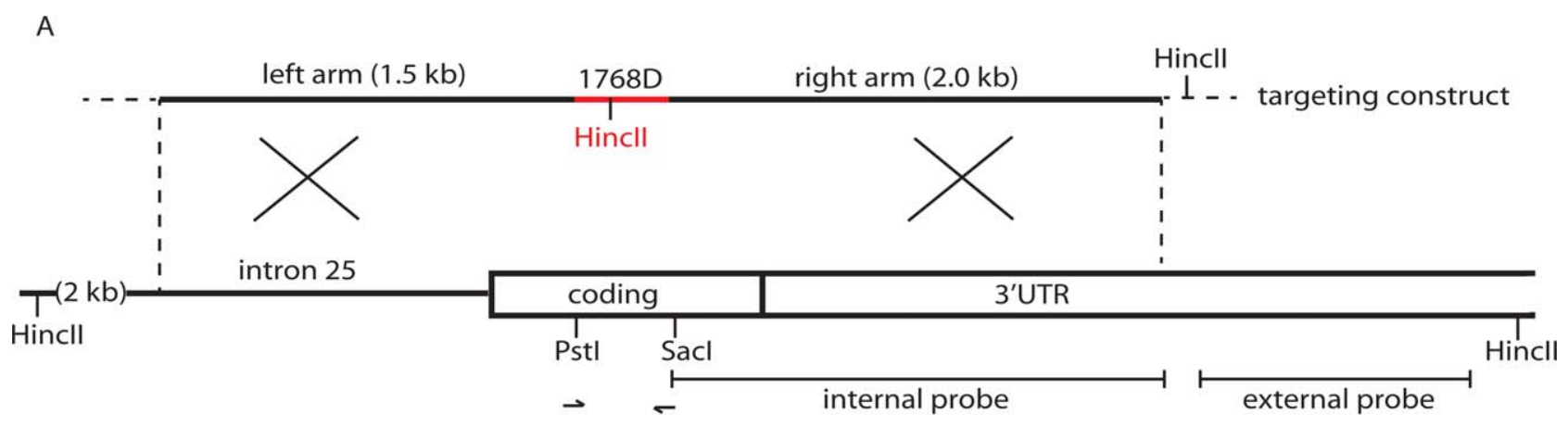

B

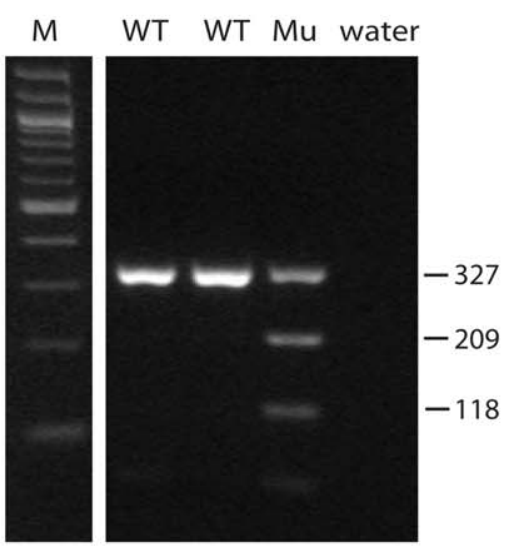

C

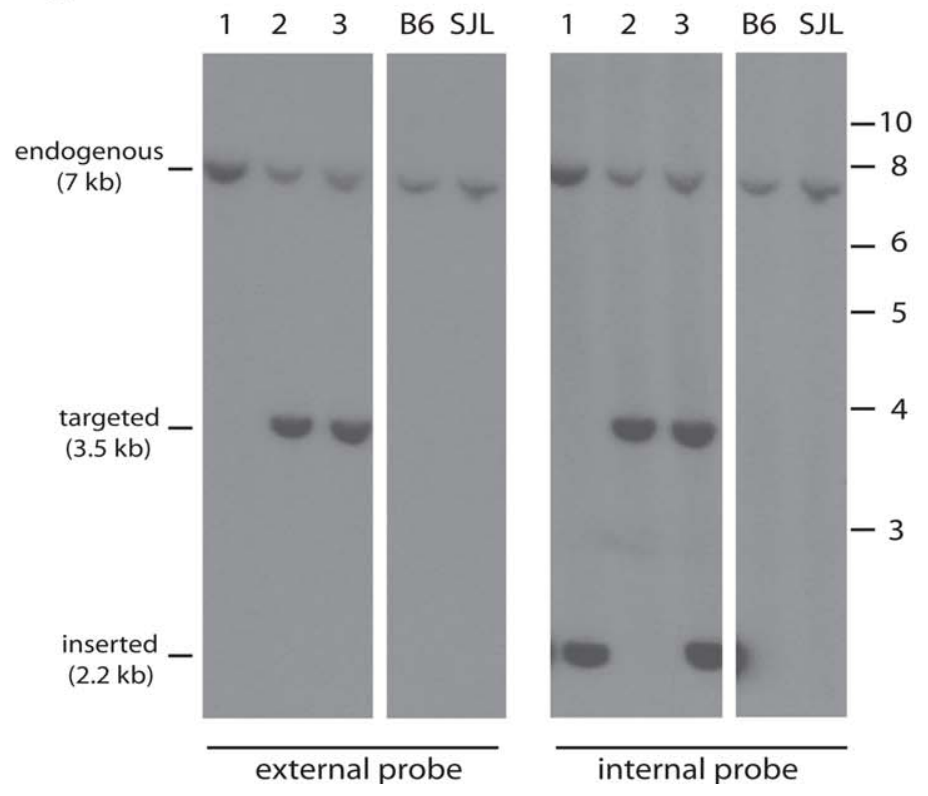

FIG. 2. Structure of the targeting construct and genotype assays to detect targeted alleles and random insertions. (A) The $6.3 \mathrm{~kb}$ targeting construct was generated from a 320 bp synthetic fragment (red) containing 9 nucleotide substitutions (Fig. 1B) plus flanking genomic fragments of 1.5 and $2.0 \mathrm{~kb}$ and the vector sequence of $3 \mathrm{~kb}$ (not shown). Arrows represent the PCR primers used to amplify a $327 \mathrm{bp}$ fragment containing the targeted site for genotyping and sequencing. The indicated external probe was used for hybridization of Southern blots with Hincll digested genomic DNA, generating a $3.5 \mathrm{~kb}$ Hincll fragment from correctly targeted Scn8a loci. The internal probe was used to detect random insertions of the targeting construct by hybridization to the internal $2.2 \mathrm{~kb}$ Hincll fragment generated from the Hincll site in the vector. (B) Detection of mice carrying the Hincll site from the targeting vector by PCR amplification of the 327 bp genomic fragment (see A) followed by digestion with Hincll. M, 100 bp ladder; WT, wild-type; Mu, mutant with the introduced Hincll site. Fragment sizes in bp. (C) Distinction between correctly targeted Scn8a and random insertion of the targeting construct by Southern blot of Hincll digested genomic DNA followed by hybridization with the external probe (left) or the internal probe (right). Three representative genomic DNA samples are shown, containing a targeted allele, a random insertion, or both. MW markers in kb at right.

specific nucleotide substitutions into the mouse genome. The $19 \%$ yield of live-born animals (67/350) is comparable to that obtained during routine generation of transgenic mice by microinjection. The $7 \%$ yield of mice carrying correctly targeted alleles means that only a single round of microinjection is required to generate a mutation of interest. In contrast, targeting of Scn8a by homologous recombination in ES cells, which do not express $S c n 8 a$, generated only 2/480 targeted clones
(0.4\%) (Levin and Meisler, 2004). The presence of closely related paralogous genes did not produce an excess of off-site mutagenesis, with 37 independent mutations in the Scn $8 a$ locus and only 9 off-site mutations in the most closely related loci, Scn $4 a$ and Scn $5 a$.

We used a targeting template containing $4 \mathrm{~kb}$ of genomic DNA in order to maximize the yield of targeted alleles. Reported yields of $2 \%$ correct targeting with a 144 bp oligonucleotide template for a pigmentation 
A $\operatorname{Sen} 8 a^{1768 D} /+(n=5)$

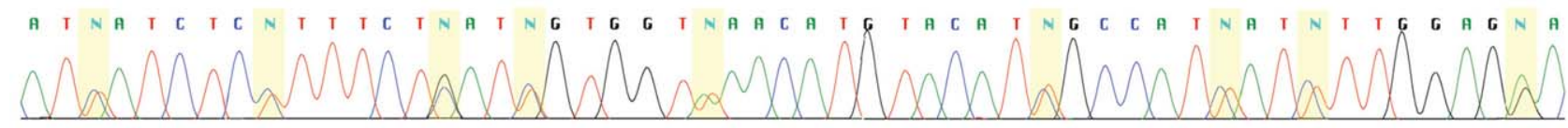

B $\operatorname{Scn} 8 \boldsymbol{a}^{\text {del }}(\mathrm{n}=19+8$ mosaic $)$

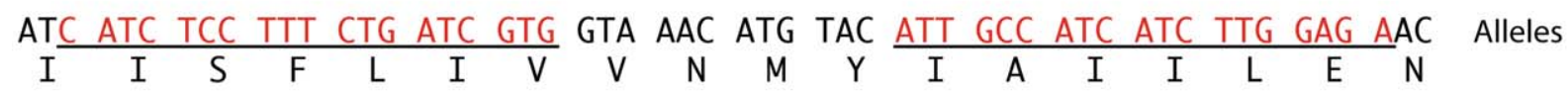

ATC ATC TCC TTT CTG ATC GTG GTA A-- ATG TAC ATT GCC ATC ATC TTG GAG AAC ATC ATC TCC TTT CTG ATC GTG GTA AA- -TG TAC ATT GCC ATC ATC TTG GAG AAC ATC ATC TCC TTT CTG ATC GTG GTA AAC --G TAC ATT GCC ATC ATC TTG GAG AAC ATC ATC TCC TTT CTG ATC GTG GTA AAC A-- TAC ATT GCC ATC ATC TTG GAG AAC ATC ATC TCC TTT CTG ATC GTG GTA --- ATG TAC ATT GCC ATC ATC TTG GAG AAC ATC ATC TCC TTT CTG ATC GTG GT- --- ATG TAC ATT GCC ATC ATC TTG GAG AAC ATC ATC TCC TTT CTG ATC GTG GTA --- -TG TAC ATT GCC ATC ATC TTG GAG AAC ATC ATC TCC TTT CTG ATC GTG GTA --- --G TAC ATT GCC ATC ATC TTG GAG AAC ATC ATC TCC TTT CTG ATC GTG GTA A-- --- TAC ATT GCC ATC ATC TTG GAG AAC ATC ATC TCC TTT CTG ATC GTG --- -- --G TAC ATT GCC ATC ATC TTG GAG AAC ATC ATC TCC TTT CTG ATC GTG GTA AAC ATG TAC ATT GCC ATC ATC TTG GAG AAC

A

ATC ATC TCC TTT CTG ATC GTG GTA AAC ATG TAC ATT GCC ATC ATC TTG GAG AAC $\wedge$ $\mathrm{T}$ 2 1 2* 1 4 1 1 2 1 2 1
ATC ATC TCC TTT CTG ATC GTG GTA AA. .TG TAC ATT GCC ATC ATC TTG GAG AAC 1 $\wedge$

C $\operatorname{Sen} 5 a^{\text {del }}(n=5)$

ATC ATC TCC TTC CTC ATC GTG GTC -...- -.- ATT GCC ATC ATC CTG GAG AAC ATC ATC TCC TTC CTC ATC GTG GTC A-- ATG TAC ATT GCC ATC ATC CTG GAG AAC ATC ATC TCC TTC CTC ATC GTG GTC AAC --G TAC ATT GCC ATC ATC CTG GAG AAC ATC ATC TCC TTC CTC ATC GTG GTC AAC ATG TAC ATT GCC ATC ATC CTG GAG AAC $\wedge$ $\mathrm{T}$

ATC ATC TCC TTC CTC ATC GTG GTC AAC ATG TAC ATT GCC ATC ATC CTG GAG AAC 1 $\hat{A}$

D Scn $4 a^{\text {del }}(n=2)$

ATC ATC TCC TTC CTC ATC GTG GT- -- -- - AC ATT GCC ATC ATC CTA GAG AAC 1 ATC ATC TCC TTC CTC ATC GTG GTC A-- - - - - - - - TC CTA GAG AAC 1

FIG. 3. TALEN generated mutations in Scn8a and off-site mutations in two sodium channel paralogs. The 327 bp fragment shown in Figure $2 \mathrm{~A}$ was amplified from the genomic DNA of 62 potential founder mice and sequenced. (A) Sequence chromatogram from a founder mouse carrying Scn8 $a^{t m 1768 D M m}$. The 9 nucleotide substitutions from the targeting construct in Figure 1B were detected in heterozygous state (yellow). (B) Genomic sequence of the Scn8a locus from 24 founder mice carrying 13 different indels. (C, D) Genomic sequence from 7 founders carrying 5 different indels in the cardiac sodium channel Scn5a and two indels in the muscle sodium channel Scn4a. The wildtype sequences are shown in Figure 1C. The number of independent alleles observed is indicated at the right. *: homozygote. 
Table 1

Genotypes and Allelic Distribution of Sodium Channel Mutations in 62 Offspring Obtained by Microinjection of TALENs and a $4 \mathrm{~kb}$ Targeting Construct

\begin{tabular}{lccc}
\hline Scn8a & Scn5a & Scn4a & \# mice \\
\hline$+/+$ & $+/+$ & $+/+$ & 33 \\
tar/+ & $+/+$ & $+/+$ & 3 \\
tar/- & $+/+$ & $+/+$ & 2 \\
$+/-$ & $+/+$ & $+/+$ & 15 \\
$+/-$ & $+/-$ & $+/+$ & 3 \\
$-/-$ & $+/+$ & $+/+$ & 2 \\
$-/-$ & $+/-$ & $+/+$ & 2 \\
$-/-$ & $+/-$ & $+/-$ & 2 \\
& & & 62 \\
\hline
\end{tabular}

Tar, targeted mutations in the endogenous Scn8a locus; -: null alleles caused by small insertions and deletions; +: wild-type.

gene (Wefers et al., 2013) and 7\% correct targeting of Fus with a 140 bp oligonucleotide template (Panda et al., 2013), indicate that construction of a targeting vector may be unnecessary for some applications. CRISPR targeting using a targeting construct produced a yield of $10 \%$ correctly targeted offspring, but with an apparently higher rate of off-site mutation among the correctly targeted mice (Yang et al., 2013). (We had no off-target mutations in the 5 correctly targeted mice). Thus, for targeting a multi-gene family, TALENs may provide greater specificity.

The p.Asn1768Asp mutation has been transmitted through the germline from two founder mice to $50 \%$ of heterozygous offspring (12/25 in one line and 13/22 in the other). The heterozygous p.Asn 1768Asp/+ offspring do exhibit the key clinical features of the patient with epileptic encephalopathy, including behavioral abnormalities, seizures, and SUDEP (sudden unexpected death in epilepsy). Unrelated visible phenotypes have not been observed. This new disease model will be valuable for analysis of the neuronal consequences of a hyperexcitable allele of $\operatorname{Scn} 8 a$, and for characterizing its response to antiseizure drugs and other treatments. Detection of novel human mutations by exome sequencing is increasing rapidly. The efficient generation of accurate mouse models using TALEN and related technology will greatly facilitate future investigations of human genetic disorders.

\section{METHODS}

\section{Scn8a Specific TALENS}

Six pairs of Scnsa-specific TALENs were designed and tested in transfected NIH 3T3 cells by PNA Bio. (Thousand Oaks, CA). The TALEN constructs employ the standard RVD code and linker between TALE and Fok1 domains (Cermak et al., 2011). Endonuclease activity was evaluated by PCR amplification of Scn8a with the primers 8aTAL-F ( $5^{\prime}$ CCATC TTTGGG ATGTC CAAC $3^{\prime}$ ) and 8aTAL-R ( $5^{\prime}$ GGATG TCCAA GCAGT
GGATT $3^{\prime}$ ) as described (http://pnabio.com/products/ TALEN.htm). The nucleotide sequences of the two TALENs shown in Figure 1A.

\section{Targeting Construct}

The template for homologous recombination was constructed as follows: (1) Synthesis of oligonucleotides of 190 and 184 bp in length with a 34 bp overlap (Integrated DNA technologies). The forward primer contained 9 nucleotide differences from the C57BL/6J genome (Fig. 1B). F oligo (5' CCCTG ACTGC AGCTT GGACA AGGAG CACCC AGGAA GTGGC TTCAA AGGGG ACTGC GGGAA CCCCT CCGTG GGCAT CTTCT TCTTC GTCAG CTACA TCATT ATCTC TTTTC TCATT GTGGT TAACA TGTAC ATCGC CATTA TTTTG GAGGA CTTCA GCGTA GCCAC AGAGG AAAGC GCCGA TCCTC TGAGC $3^{\prime}$ ), the $\mathrm{R}$ oligo (5' GGCGA TGAGC TCGAT GGTGT TGGGC TTGGG TACTC GGAGC GGATG CTCCA GGGCG TCGGC AAAGT CGGCC AGCTT ACAGT ACTCG ATGAA CTGGG TGGCA TCAGG ATCAA ACTTC TCCCA GATCT CATAG AAAGT CTCGA AGTCG TCCTC GCTCA GAGGA TCGGC GCTTT CCTCT GTGGC TAC $3^{\prime}$ ). The combined oligonucleotides acted as primer and template in a PCR reaction containing $1 \times$ Phusion $\mathrm{HF}$ buffer, $0.2 \mathrm{mM}$ dNTPs and 1 unit Phusion Taq DNA Polymerase (Thermo Scientific) in $50 \mu \mathrm{l}$. The reaction was incubated at $98^{\circ} \mathrm{C}$ for $30 \mathrm{~s}$ followed by 35 cycles of $98^{\circ} \mathrm{C}$ for $10 \mathrm{~s}$ and $72^{\circ} \mathrm{C}$ for $15 \mathrm{~s}$, with a final $10 \mathrm{~min}$ extension at $72^{\circ} \mathrm{C}$. The $340 \mathrm{bp}$ product was gel purified, sequentially digested with PstI and SacI to generate a 320 bp fragment, and ligated into the $2.5 \mathrm{~kb}$ vector pSP72 (Promega) to generate clone 1. (2) PCR amplification of the $1.5 \mathrm{~kb}$ left arm fragment from C57BL/6J genomic DNA was carried out with the forward primer $5^{\prime}$ CACAC ACTCG AGTCT TCTGG CTTAA AACCA TCAGG $3^{\prime}$ and the reverse primer $5^{\prime}$ TCCAA GCTGC AGTCA GGGGG GCGGT TCAGG ATTG $3^{\prime}$. The gel-purified fragment was digested with PstI and XhoI and ligated into clone 1 to generate clone 2 . (3) The $2.0 \mathrm{~kb}$ right arm fragment was amplified from genomic DNA using the forward primer 5' CAGTT CATCG AGTAC TGTAA GCTGG 3' and the reverse primer $5^{\prime}$ ACACA CATCG ATCTT ATCTC AGCCA ACACT GCTGT C $3^{\prime}$. The gel purified fragment was digested with SacI and ClaI and ligated into clone 2 to generate the full length $6.3 \mathrm{~kb}$ targeting construct.

\section{Microinjection of TALEN mRNA and Targeting Construct into Fertilized Eggs}

Polyadenylated and $5^{\prime}$ capped mRNA was synthesized from each TALEN using the mMessage mMachine T7 Ultra Kit and purified using the MEGAclear Kit (Ambion by Life Technologies, Carlsbad, CA). Circular targeting construct DNA $(2.5 \mathrm{ng} / \mu \mathrm{l})$ and TALEN mRNAs (10 or 20 $\mathrm{ng} / \mu \mathrm{l}$ each) in $10 \mathrm{~m} M$ Tris- $\mathrm{HCl}, 0.1 \mathrm{~m} M$ EDTA were 
microinjected into the pronucleus of $(\mathrm{C} 57 \mathrm{BL} / 6 \mathrm{~J} \times$ SJL)F2 fertilized eggs in the University of Michigan Transgenic Animal Core, Thom Saunders, Director (www.med.umich.edu/tamc/).

\section{Genotyping Potential Founders}

Tail biopsies were digested with $1 \mu \mathrm{g} / \mu \mathrm{l}$ proteinase $\mathrm{K}$ in $100 \mathrm{~m} M \mathrm{NaCl}, 100 \mathrm{~m} M$ EDTA, $50 \mathrm{~m} M$ TrisHCl, $\mathrm{pH}$ 8.0, 1\% SDS followed by extraction with phenol and chloroform and precipitation with ethanol. A 327 bp genomic fragment containing the targeted site of Scn $8 a$ was amplified with the primers Tar-F (5' TGACT GCAGC TTGGA CAAGG AGC $3^{\prime}$ ) and Tar-R (5' TCGAT GGTGT TGGGC TTGGG TAC $3^{\prime}$ ). PCR products were digested with HincII and analyzed on 2\% agarose gels to identify mice carrying the introduced HincII site in the TALEN spacer. For Southern blots, $10 \mu \mathrm{g}$ of DNA was digested with HincII and electrophoresed through $0.8 \%$ agarose. Fragments were transferred to Zetaprobe GT nylon membrane (BioRad Laboratories) and hybridized with ${ }^{32} \mathrm{P}$-dCTP-labeled probes. The external probe for detection of correctly targeted Scn8a was amplified from C57BL/6J genomic DNA with the primers $3^{\prime}$ UTR-F (5' CCACT TGGTC TTGTT TCTAC GACG $3^{\prime}$ ) and $3^{\prime}$ UTR-R ( $5^{\prime}$ CCTAG CAGGA TCAAA TAGCT GTTGC $3^{\prime}$ ). After autoradiography, the blot was stripped and reprobed with the $2.0 \mathrm{~kb}$ right arm DNA fragment (internal probe) to detect random transgene insertions which contain the HincII site from the vector (Fig. 1A). Molecular weight markers, $100 \mathrm{bp}$ ladder and $1 \mathrm{~kb}$ ladder, from New England Biolabs.

\section{Sequencing of Targeted Scn8a and Identification of Indels}

The 327 bp genomic fragment containing the targeted site of Scn8a locus was amplified as described in the preceding section and sequenced from both strands by Sanger Sequencing in the University of Michigan Sequencing Core. The corresponding fragments of $S c n 4 a$ and $S c n 5 a$ were amplified using the primers Scn $4 a$-F ( $5^{\prime}$ CGACA TTGGA GAACC CAGGC AC $\left.3^{\prime}\right)$, Scn $4 a$-R ( $5^{\prime}$ AAGCT TGATC TTATT GGGCT TGGCA $3^{\prime}$ ), Scn $5 a$-F ( $5^{\prime}$ AACCT GCCCA ACAGC AATGG CTC $\left.3^{\prime}\right)$ and $s c n 5 a-\mathrm{R}\left(5^{\prime}\right.$ AACCT GCCCA ACAGC AATGG CTC $\left.3^{\prime}\right)$.

\section{Animals}

Mice were housed and cared for in accordance with NIH guidelines. Experiments were approved by the University of Michigan Committee on the Use and Care of Animals. Mutant mice are available to the research community.

\section{ACKNOWLEDGMENTS}

The authors thank Thom Saunders (Director, University of Michigan Transgenic Animal Model Core) and Erin Lee
(PNA Bio Inc) for helpful discussions. Microinjection was carried out by Wanda Filipiak at the Transgenic Animal Model Core.

\section{LITERATURE CITED}

Allen AS, Berkovic SF, Cossette P, Delanty N, Dlugos D, Eichler EE, Epstein MP, Glauser T, Goldstein DB, Han Y, Heinzen EL, Hitomi Y, Howell KB, Johnson MR, Kuzniecky R, Lowenstein DH, Lu YF, Madou MR, Marson AG, Mefford HC, Esmaeeli Nieh S, O'Brien TJ, Ottman R, Petrovski S, Poduri A, Ruzzo EK, Scheffer IE, Sherr EH, Yuskaitis CJ, Abou-Khalil B, Alldredge BK, Bautista JF, Berkovic SF, Boro A, Cascino GD, Consalvo D, Crumrine P, Devinsky O, Dlugos D, Epstein MP, Fiol M, Fountain NB, French J, Friedman D, Geller EB, Glauser T, Glynn S, Haut SR, Hayward J, Helmers SL, Joshi S, Kanner A, Kirsch HE, Knowlton RC, Kossoff EH, Kuperman R, Kuzniecky R, Lowenstein DH, McGuire SM, Motika PV, Novotny EJ, Ottman R, Paolicchi JM, Parent JM, Park K, Poduri A, Scheffer IE, Shellhaas RA, Sherr EH, Shih JJ, Singh R, Sirven J, Smith MC, Sullivan J, Lin Thio L, Venkat A, Vining EP, Von Allmen GK, Weisenberg JL, Widdess-Walsh $\mathrm{P}$, Winawer MR. 2013. De novo mutations in epileptic encephalopathies. Nature 501:217-221.

Boiko T, Rasband MN, Levinson SR, Caldwell JH, Mandel G, Trimmer JS, Matthews G. 2001. Compact myelin dictates the differential targeting of two sodium channel isoforms in the same axon. Neuron 30:91-104.

Carvill GL, Heavin SB, Yendle SC, McMahon JM, O'Roak BJ, Cook J, Khan A, Dorschner MO, Weaver M, Calvert S, Malone S, Wallace G, Stanley T, Bye AM, Bleasel A, Howell KB, Kivity S, Mackay MT, Rodriguez-Casero V, Webster R, Korczyn A, Afawi Z, Zelnick N, Lerman-Sagie T, Lev D, Moller RS, Gill D, Andrade DM, Freeman JL, Sadleir LG, Shendure J, Berkovic SF, Scheffer IE, Mefford HC. 2013. Targeted resequencing in epileptic encephalopathies identifies de novo mutations in CHD2 and SYNGAP1. Nat Genet 45:825-830.

Catterall WA, Dib-Hajj S, Meisler MH, Pietrobon D. 2008. Inherited neuronal ion channelopathies: new windows on complex neurological diseases. J Neurosci 28:11768-11777.

Cermak T, Doyle EL, Christian M, Wang L, Zhang Y, Schmidt C, Baller JA, Somia NV, Bogdanove AJ, Voytas DF. 2011. Efficient design and assembly of custom TALEN and other TAL effector-based constructs for DNA targeting. Nucleic Acids Res 39: e82.

Davies B, Davies G, Preece C, Puliyadi R, Szumska D, Bhattacharya S. 2013. Site specific mutation of the 
Zic2 locus by microinjection of TALEN mRNA in mouse CD1, C3H and C57BL/6J oocytes. PLoS One 8:e60216.

Doyle EL, Booher NJ, Standage DS, Voytas DF, Brendel VP, Vandyk JK, Bogdanove AJ. 2012. TAL EffectorNucleotide Targeter (TALE-NT) 2.0: tools for TAL effector design and target prediction. Nucleic Acids Res 40:W117-W122.

Levin SI, Meisler MH. 2004. Floxed allele for conditional inactivation of the voltage-gated sodium channel Scn8a (NaV1.6). Genesis 39:234-239.

Lorincz A, Nusser Z. 2008. Cell-type-dependent molecular composition of the axon initial segment. J Neurosci 28:14329-14340.

McKinney BC, Chow CY, Meisler MH, Murphy GG. 2008. Exaggerated emotional behavior in mice heterozygous null for the sodium channel Scn8a (Nav1.6). Genes Brain Behav 7:629-638.

Meisler MH, O'Brien JE, Sharkey LM. 2010. Sodium channel gene family: Epilepsy mutations, gene interactions and modifier effects. J Physiol 588:1841-1848.

Menke DB. 2013. Engineering subtle targeted mutations into the mouse genome. Genesis 51:605-618.

Meyer M, Ortiz O, Hrabe de Angelis M, Wurst W, Kuhn R. 2012. Modeling disease mutations by gene targeting in one-cell mouse embryos. Proc Natl Acad Sci U S A 109:9354-9359.

O'Brien JE, Meisler MH. 2013. Sodium channel (Na1.6): Properties and mutations in epileptic encephalopathy and intellectual disability. Front Genet 4:213.

Panda SK, Wefers B, Ortiz O, Floss T, Schmid B, Haass C, Wurst W, Kuhn R. 2013. Highly efficient targeted mutagenesis in mice using TALENs. Genetics 195: 703-713.

Qiu Z, Liu M, Chen Z, Shao Y, Pan H, Wei G, Yu C, Zhang L, Li X, Wang P, Fan HY, Du B, Liu B, Li D. 2013. High-efficiency and heritable gene targeting in mouse by transcription activator-like effector nucleases. Nucleic Acids Res 41:e120.

Rauch A, Wieczorek D, Graf E, Wieland T, Endele S, Schwarzmayr T, Albrecht B, Bartholdi D, Beygo J, Di Donato N, Dufke A, Cremer K, Hempel M, Horn D,
Hoyer J, Joset P, Ropke A, Moog U, Riess A, Thiel CT, Tzschach A, Wiesener A, Wohlleber E, Zweier C, Ekici AB, Zink AM, Rump A, Meisinger C, Grallert H, Sticht H, Schenck A, Engels H, Rappold G, Schrock E, Wieacker P, Riess O, Meitinger T, Reis A, Strom TM. 2012. Range of genetic mutations associated with severe non-syndromic sporadic intellectual disability: An exome sequencing study. Lancet 380: 1674-1682.

Sung YH, Baek IJ, Kim DH, Jeon J, Lee J, Lee K, Jeong D, Kim JS, Lee HW. 2013. Knockout mice created by TALEN-mediated gene targeting. Nat Biotechnol 31: 23-24.

Trudeau MM, Dalton JC, Day JW, Ranum LP, Meisler MH. 2006. Heterozygosity for a protein truncation mutation of sodium channel SCN8A in a patient with cerebellar atrophy, ataxia, and mental retardation. J Med Genet 43:527-530.

Van Wart A, Trimmer JS, Matthews G. 2007. Polarized distribution of ion channels within microdomains of the axon initial segment. J Comp Neurol 500:339352 .

Veeramah KR, O'Brien JE, Meisler MH, Cheng X, DibHajj SD, Waxman SG, Talwar D, Girirajan S, Eichler EE, Restifo LL, Erickson RP, Hammer MF. 2012. De novo pathogenic SCN8A mutation identified by whole-genome sequencing of a family quartet affected by infantile epileptic encephalopathy and SUDEP. Am J Hum Genet 90:502-510.

Wefers B, Meyer M, Ortiz O, Hrabe de Angelis M, Hansen J, Wurst W, Kuhn R. 2013. Direct production of mouse disease models by embryo microinjection of TALENs and oligodeoxynucleotides. Proc Natl Acad Sci U S A 110:3782-3787.

Yang H, Wang H, Shivalila CS, Cheng AW, Shi L, Jaenisch R. 2013. One-step generation of mice carrying reporter and conditional alleles by CRISPR/Casmediated genome engineering. Cell 154:13701379.

Zakon HH. 2012. Adaptive evolution of voltage-gated sodium channels: The first 800 million years. Proc Natl Acad Sci U S A 109 (Suppl 1):10619-10625. 